\title{
Article \\ The Role of Noise in Specific Detectivity of InAs/GaSb Superlattice MWIR Bariodes
}

\author{
Krzysztof Czuba $^{1} \mathbb{D}$, tukasz Ciura ${ }^{2} \mathbb{D}$, Iwona Sankowska ${ }^{1}$, Ewa Papis-Polakowska ${ }^{1}$ and Agata Jasik ${ }^{1, *(\mathbb{D})}$ \\ 1 Łukasiewicz Research Network-Institute of Microelectronics and Photonics, al. Lotników 32/46, \\ 02-668 Warsaw, Poland; krzysztof.czuba@imif.lukasiewicz.gov.pl (K.C.); \\ iwona.sankowska@imif.lukasiewicz.gov.pl (I.S.); ewa.papis.polakowska@imif.lukasiewicz.gov.pl (E.P.-P.) \\ 2 Department of Electronics Fundamentals, Rzeszow University of Technology, W. Pola 2, \\ 35-959 Rzeszow, Poland; lciura@prz.edu.pl \\ * Correspondence: agata.jasik@imif.lukasiewicz.gov.pl
}

Citation: Czuba, K.; Ciura, Ł.; Sankowska, I.; Papis-Polakowska, E.; Jasik, A. The Role of Noise in Specific Detectivity of InAs/GaSb Superlattice MWIR Bariodes. Sensors 2021, 21, 7005. https://doi.org/10.3390/ s21217005

Academic Editor: Zahra Sharif Khodaei

Received: 2 October 2021

Accepted: 19 October 2021

Published: 22 October 2021

Publisher's Note: MDPI stays neutral with regard to jurisdictional claims in published maps and institutional affiliations.

Copyright: (C) 2021 by the authors Licensee MDPI, Basel, Switzerland. This article is an open access article distributed under the terms and conditions of the Creative Commons Attribution (CC BY) license (https:// creativecommons.org/licenses/by/ $4.0 /)$.

\begin{abstract}
In this paper, the results of the electrical, noise, and optical characterization of p-i-n and p-Bi-n diodes with AlSb and $4 \mathrm{ML}$ AlSb/8 ML GaSb superlattice barriers in High-Operating Temperature conditions, are presented. Experimental and theoretical noise parameters were compared. Both dark current and noise analysis showed that the $\mathrm{p}-\mathrm{B}_{\mathrm{p}_{-} \text {bulk }}-\mathrm{i}-\mathrm{n}$ bariode had the best performance. $P-i-n$ photodiodes had the highest experimental value of specific detectivity $\left(D^{*}\right)$ of $6.16 \times 10^{9}$ Jones at $210 \mathrm{~K}$ and zero bias. At about $-1 \mathrm{~V}$ reverse bias, the bariode with AlSb/GaSb electron barrier caught up to it and both devices achieved $\mathrm{D}^{*}=(1-1.1) \times 10^{8}$ Jones. Further optimization of the superlattice-based electron barrier should result in the improvement of bariode performance at a smaller bias, at which better noise performance is more pronounced. It was shown that neglecting the low-frequency noise component can lead to a significant overestimation of detectivity. The simple method of incorporation of low-frequency noise contribution in the detectivity calculation, without time-consuming measurements, has been proposed.
\end{abstract}

Keywords: infrared sensors; InAs/GaSb superlattice; barrier photodiode; noise performance; specific detectivity; low-frequency noise

\section{Introduction}

Infrared photodetectors are widely used in many branches of modern society such as environment monitoring, imaging, medicine, spectroscopy, or the military. Presently, mercury-cadmium-telluride-based technology dominates the market. However, national and international legislation works to eliminate heavy metal usage in the production of consumer products, including $\mathrm{Hg}$ and $\mathrm{Cd}$. As a result, research to find better and safer materials is undergoing in facilities around the world. At present, two of the best candidates are antimonide-based type-II superlattices (SL) InAs/GaSb and InAs/InAsSb [1-5]. They allow for the utilization of bandgap engineering design structures with long-wavelength absorption edge practically in the entire mid-infrared spectral range [6]. Furthermore, both their growth and processing technology matured in the last decade to the point, at which discrete photodetectors, as well as focal plane arrays based on them, are becoming more common [7-9].

Lately, more and more attention is paid to the High-Operating Temperature (HOT) photodetectors, which work at temperatures from $200 \mathrm{~K}$ to $300 \mathrm{~K}$ and beyond [10-12]. In such devices, low temperatures are achieved through the use of thermoelectric cooling. They have many advantages over cryogenically cooled detectors. In particular, they allow for further decreasing the size and weight, lowering production costs as well as better power usage efficiency. As a result, their applications can be more versatile and more easily spread into the consumer market. 
Increasing the operating temperature of SL-based infrared photodetectors can be achieved using different approaches. One is to use novel architecture, such as in Interband Cascade Detectors or Quantum Cascade Detectors $[13,14]$. Presently, the main disadvantage of such structures is their complexity. They require considerable computational effort during the design and optimization stages. Furthermore, they are hard to realize epitaxially, as the margin of error required for their proper operation is very small. Another approach is to introduce unipolar carrier barriers into mature detector designs (e.g., photoconductor or $\mathrm{p}-\mathrm{i}-\mathrm{n}$ photodiode), the purpose of which is the suppression of dark current and noise without negatively influencing the photocurrent [15-17]. The barriers can be placed for one or two types of carriers, depending on the detector structure. They can be made of either bulk material (e.g., AlSb, AlAsSb, AlGaSb) or superlattice (e.g., InAs/AlSb, AlSb/GaSb). The latter allows for better optimization of the photodetector band structure due to the utilization of bandgap engineering.

This paper is focused on photodiodes with $\left(p-B_{p}-i-n\right)$ and without $(p-i-n)$ electron barriers, based on a double heterojunction design. The $\mathrm{B}_{\mathrm{p}}$ in $\mathrm{p}-\mathrm{B}_{\mathrm{p}}-\mathrm{i}-\mathrm{n}$ pertains to a $\mathrm{p}$-type electron barrier made of either AlSb or AlSb/GaSb superlattice. The analysis of dark current, noise, and optical response is presented. The emphasis was put on the role of noise in the performance of these infrared photodetectors. Furthermore, a comparison between two semi-empirical approximations (the first including thermal and shot noise, and the second including thermal, shot, and low-frequency noise) and actual measurements is presented. The issues arising from the omission of low-frequency noise during the calculation of specific detectivity and resulting errors are addressed. Usually, noise figures for InAs/GaSb-superlattice-based devices are given for low temperatures $<150 \mathrm{~K}$, which is understandable since cryogenically-cooled detectors are most commonly used [18-20]. In this paper, all noise characteristics are shown in the HOT temperature range in addition to the low-temperature characterization. Furthermore, to the best of our knowledge, there are no low-frequency noise measurements reported for bariodes on GaAs substrate, in contrast to recently reported results for various detectors on GaSb substrate $[19,21,22]$.

\section{Fabrication of InAs/GaSb Superlattice Photodetectors}

In this work, three types of photodiodes were compared, namely $p-i-n, p-B_{p \_b u l k}-i-n$ with AlSb electron barrier, and $\mathrm{p}-\mathrm{B}_{\mathrm{p}_{-} \mathrm{SL}}-\mathrm{i}-\mathrm{n}$ with type-I $\mathrm{AlSb} / \mathrm{GaSb}$ superlattice electron barrier. In Figure 1, schematic diagrams of each photodetector are shown. All samples were deposited on (100) GaAs substrates.

(a)

\begin{tabular}{|c|c|c|}
\hline $100 \mathrm{~nm}$ & $\mathrm{GaSb}: \mathrm{Be}$ & $\mathrm{p}=1 \times 10^{18} \mathrm{~cm}^{-3}$ \\
\hline $100 \mathrm{~nm}$ & $\mathrm{GaSb}: \mathrm{Be}$ & $\mathrm{p}=2 \times 10^{17} \mathrm{~cm}^{-3}$ \\
\hline \multicolumn{3}{|c|}{ 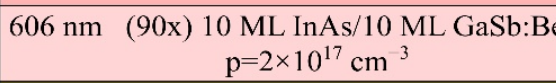 } \\
\hline \multicolumn{3}{|c|}{$\begin{array}{c}2692 \mathrm{~nm}(400 \mathrm{x}) 10 \mathrm{ML} \text { InAs/10 ML GaSb } \\
\text { undoped }\end{array}$} \\
\hline \multicolumn{3}{|c|}{$\begin{array}{c}404 \mathrm{~nm} \begin{array}{c}\text { (60x) } 10 \mathrm{ML} \text { InAs:Te/10 ML GaSt } \\
\mathrm{n}=5 \times 10^{17} \mathrm{~cm}^{-3}\end{array} \\
\end{array}$} \\
\hline $100 \mathrm{~nm}$ & GaSb:Te & $\mathrm{n}=5 \times 10^{16} \mathrm{~cm}^{-3}$ \\
\hline $5000 \mathrm{~nm}$ & GaSb:Te & $\mathrm{n}=2 \times 10^{18} \mathrm{~cm}^{-3}$ \\
\hline \multicolumn{3}{|c|}{ GaAs substrate } \\
\hline
\end{tabular}

(b)

\begin{tabular}{|c|c|c|}
\hline $30 \mathrm{~nm}$ & $\mathrm{GaSb}: \mathrm{Be}$ & $\mathrm{p}=2 \times 10^{18} \mathrm{~cm}^{-3}$ \\
\hline $30 \mathrm{~nm}$ & $\mathrm{GaSb}: \mathrm{Be}$ & $\mathrm{p}=5 \times 10^{17} \mathrm{~cm}^{-3}$ \\
\hline $50 \mathrm{~nm}$ & $\mathrm{GaSb}: \mathrm{Be}$ & $\mathrm{p}=3 \times 10^{17} \mathrm{~cm}^{-3}$ \\
\hline $50 \mathrm{~nm}$ & AlSb:Be & $\mathrm{p}=1 \times 10^{17} \mathrm{~cm}^{-3}$ \\
\hline \multicolumn{3}{|c|}{$\begin{array}{c}2956 \mathrm{~nm} \text { (440x) } 10 \mathrm{ML} \text { InAs/10 ML GaSb } \\
\text { undoped }\end{array}$} \\
\hline $350 \mathrm{~nm}$ & GaSb:Te & $\mathrm{n}=5 \times 10^{16} \mathrm{~cm}^{-3}$ \\
\hline $2125 \mathrm{~nm}$ & GaSb:Te & $\mathrm{n}=3 \times 10^{18} \mathrm{~cm}^{-3}$ \\
\hline \multicolumn{3}{|c|}{ GaAs substrate } \\
\hline
\end{tabular}

(c)

\begin{tabular}{|ccc|}
\hline $30 \mathrm{~nm}$ & GaSb:Be & $\mathrm{p}=2 \times 10^{18} \mathrm{~cm}^{-3}$ \\
\hline $30 \mathrm{~nm}$ & GaSb:Be & $\mathrm{p}=5 \times 10^{17} \mathrm{~cm}^{-3}$ \\
\hline $50 \mathrm{~nm}$ & GaSb:Be & $\mathrm{p}=3 \times 10^{17} \mathrm{~cm}^{-3}$ \\
\hline $\begin{array}{r}59 \mathrm{~nm} \quad(16 \mathrm{x}) \\
4 \mathrm{ML} \mathrm{AlSb}: \mathrm{Be} / 8 \mathrm{ML} \mathrm{GaSb}: \mathrm{Be} \\
\mathrm{p}=1 \times 10^{17} \mathrm{~cm}^{-3}\end{array}$ \\
$\begin{array}{c}2970 \mathrm{~nm}(440 \mathrm{x}) 10 \mathrm{ML} \text { InAs } / 10 \mathrm{ML} \mathrm{GaSb} \\
\text { undoped }\end{array}$ \\
\hline $350 \mathrm{~nm} \quad$ GaSb:Te $\mathrm{n}=5 \times 10^{16} \mathrm{~cm}^{-3}$ \\
\hline $2000 \mathrm{~nm}$ & GaSb:Te $\mathrm{n}=3 \times 10^{18} \mathrm{~cm}^{-3}$ \\
\hline \multicolumn{3}{|c|}{ GaAs substrate } \\
\hline
\end{tabular}

Figure 1. Schematic diagrams of photodiodes: (a) p-i-n, (b) p-B p_bulk $-\mathrm{i}-\mathrm{n}$ with AlSb barrier, and (c) p-B $\mathrm{B}_{\mathrm{p}} \mathrm{SL}-\mathrm{i}-\mathrm{n}$ with 4 ML $\mathrm{AlSb} / 8 \mathrm{ML}$ GaSb superlattice barrier. 
Photodetector heterostructures were grown using molecular beam epitaxy in Riber 32P reactor. In both types of structures, p-type and n-type contact layers were made of highly doped $\left(\sim 10^{18} \mathrm{~cm}^{-3}\right) \mathrm{GaSb}$ material. The absorption region consisted of 400 to 440 periods of type-II $10 \mathrm{ML}$ InAs/10 ML GaSb superlattice with InSb-like and GaAs-like interfaces. The epitaxial growth of the superlattice was described elsewhere [23]. Before fabrication of p- $B_{p_{-}} \mathrm{SL}^{-i-n}$ photodiodes, the growth of $4 \mathrm{ML}$ AlSb / $8 \mathrm{ML}$ GaSb superlattice was optimized. A series of test processes were performed, which culminated in high-quality material. In Figure $2 \mathrm{a}$, the $2 \theta$ / $\omega$ curve measured for AlSb/GaSb superlattice using the high-resolution $\mathrm{x}$-ray diffraction (HRXRD) method is shown. From its analysis, the following information was obtained: AlSb layer thickness-4.1 ML (12.5 $\AA$; ML stands for monolayer), GaSb layer thickness-8.3 ML $(25.3 \AA)$, and perpendicular lattice mismatch $(\Delta \mathrm{a} / \mathrm{a})_{\perp}$ of $4240 \mathrm{ppm}$. The latter is defined as follows:

$$
(\Delta \mathrm{a} / \mathrm{a})_{\perp}=\frac{\mathrm{a}_{\perp \_\mathrm{SL} 0}-\mathrm{a}_{\perp \_\mathrm{GaSb}}}{\mathrm{a}_{\perp_{-} \mathrm{GaSb}}}
$$

where $\mathrm{a}_{\perp \_S \mathrm{~S} 0}$ is the perpendicular lattice constant of the superlattice, for which lattice mismatch is calculated, and $\mathrm{a}_{\perp \_\mathrm{GaSb}}$ is the perpendicular lattice constant for GaSb substrate (for test $\mathrm{AlSb} / \mathrm{GaSb}$ superlattice) or GaSb buffer layer (for photodiode/bariode structures). The zeroth-order satellite peak has an FWHM of 144 arcsec. The presence of Pendellösung peaks confirmed parallelism of crystallographic planes. Furthermore, this AlSb/GaSb superlattice exhibited a smaller lattice-mismatch to the GaSb than bulk AlSb.

(a)

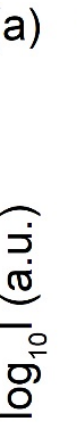

10

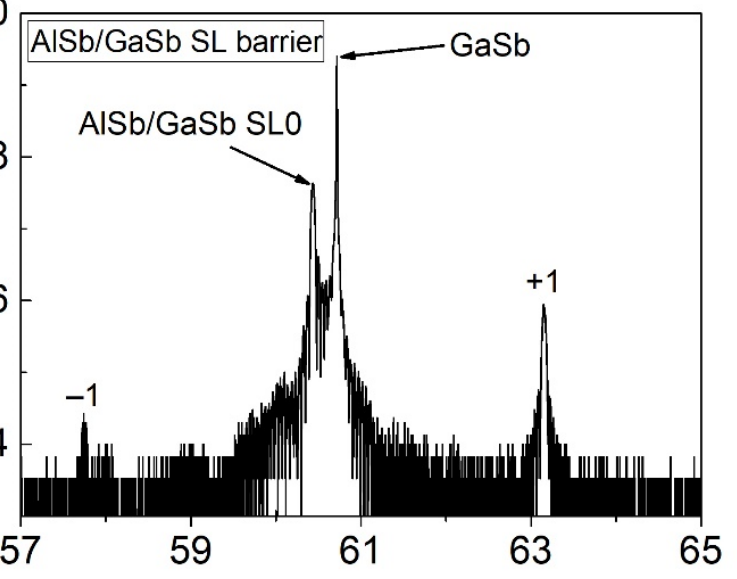

57

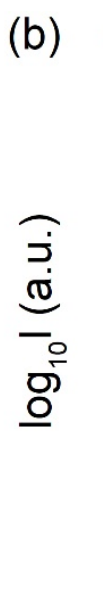

(b)

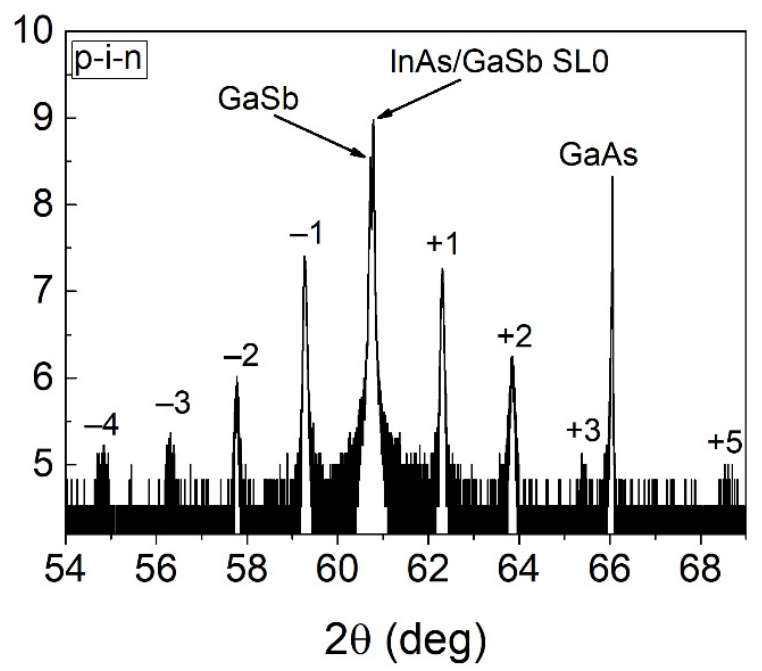

(c)

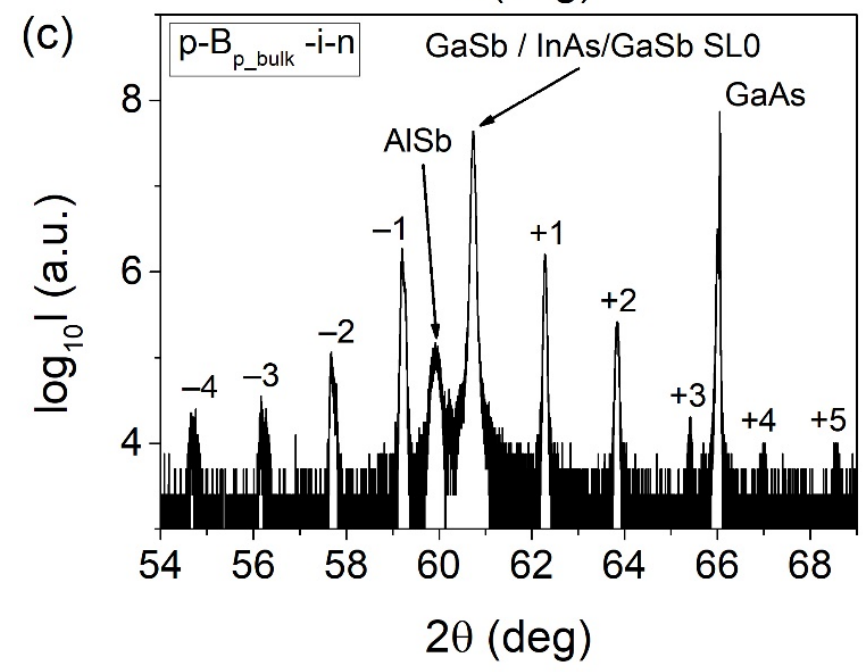

$2 \theta$ (deg) (d)

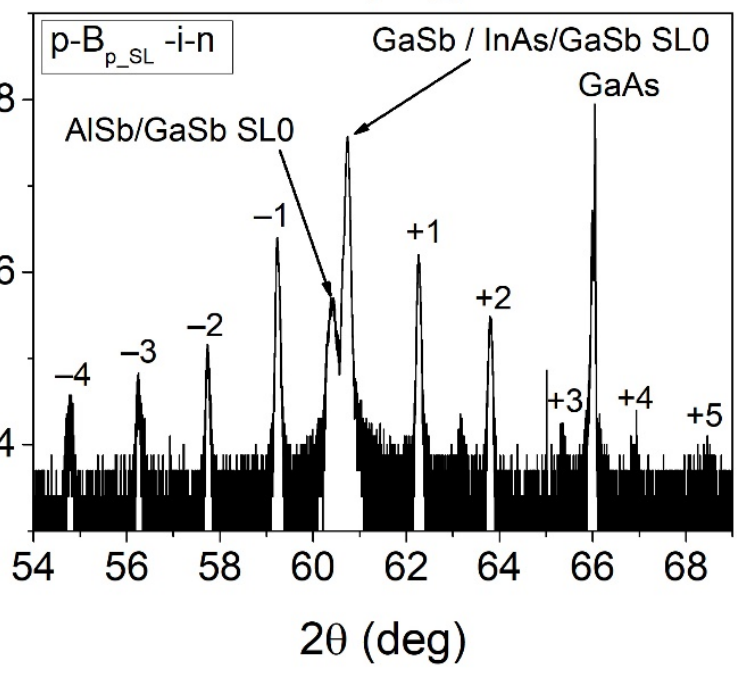

Figure 2. Measured $2 \theta / \omega$ curves for (a) 4 ML AlSb/8 ML GaSb barrier superlattice and photodiodes: (b) p-i-n, (c) p-B p_bulk $^{-}$ i-n with AlSb barrier, (d) p-B_s_sL-i-n with $4 \mathrm{ML}$ AlSb/8 ML GaSb superlattice barrier. 
Device heterostructures underwent structural quality tests using the HRXRD method. In Figure $2 b-d, 2 \theta / \omega$ curves are shown. The summary of structural details of photodiode heterostructures under consideration and lattice mismatch $(\Delta \mathrm{a} / \mathrm{a})_{\perp}$ between both absorber superlattices and barriers and GaSb buffer are given in Table 1. For all samples, higherorder satellite peaks up to the fifth order are observable, which is an indication of their high quality. The AlSb/GaSb superlattice electron barrier in $\mathrm{p}-\mathrm{B}_{\mathrm{p} \_\mathrm{SL}}-\mathrm{i}-\mathrm{n}$ heterostructure differed slightly from the test one. The layer thicknesses were AlSb-4.4 ML, GaSb-7.6 ML, and $(\Delta \mathrm{a} / \mathrm{a})_{\perp}$ was $4950 \mathrm{ppm}$.

Table 1. The summary of structural details and lattice mismatch for photodetector heterostructures obtained from HRXRD characterization.

\begin{tabular}{|c|c|c|c|}
\hline Structure & p-i-n & p-Bp_bulk-i-n & p-Bp_SL-i-n \\
\hline \multicolumn{4}{|c|}{ Absorber } \\
\hline GaAs IF thickness (ML/Å) & $0.5 / 1.5$ & $0.5 / 1.4$ & $0.5 / 1.4$ \\
\hline InAs layer thickness (ML/ $\mathrm{A})$ & $10.0 / 30.3$ & $9.9 / 30$ & $10.2 / 31$ \\
\hline InSb IF thickness (ML/ $\mathrm{A})$ & $1.5 / 4.8$ & $1.5 / 5.0$ & $1.5 / 5.0$ \\
\hline GaSb layer thickness (ML/ ̊̊) & $10.1 / 30.7$ & $9.8 / 30$ & $9.9 / 30.1$ \\
\hline$(\Delta \mathrm{a} / \mathrm{a})_{\perp}(\mathrm{ppm})$ & -920 & -280 & -280 \\
\hline \multicolumn{4}{|c|}{ electron barrier } \\
\hline type & - & bulk AlSb & $\mathrm{AlSb} / \mathrm{GaSb} \mathrm{SL}$ \\
\hline AlSb layer thickness (ML/ $\AA$ ) & - & $-/ 500$ & $4.4 / 13.6$ \\
\hline GaSb layer thickness (ML/Å) & - & - & $7.6 / 23.1$ \\
\hline$(\Delta \mathrm{a} / \mathrm{a})_{\perp}(\mathrm{ppm})$ & - & 11,800 & 4950 \\
\hline
\end{tabular}

Photodetectors were designed to operate in back-side illumination configuration and p-type contact layers are on the top of the structure. There were three reasons behind this choice. Firstly, it was to minimize losses related to the high free-carrier absorption in p-type $\mathrm{GaSb}$ in the mid-wavelength spectral range. Secondly, materials used as electron barriers have a large value of $(\Delta \mathrm{a} / \mathrm{a})_{\perp}$ to the buffer, namely 11,800 ppm for AlSb and $4950 \mathrm{ppm}$ for $4 \mathrm{ML} \mathrm{AlSb} / 8 \mathrm{ML} \mathrm{GaSb}$. It could result in worsening of both structural and optical quality of $10 \mathrm{ML}$ InAs/10 ML GaSb absorber superlattice if grown on top of such barrier layers. It would also negatively impact figures of merit of the photodetector. Finally, a double pass of infrared light through the absorption region could be achieved in such a configuration due to reflection from the top contact. Barriers were intentionally doped with beryllium to minimize the effects of valence band offsets between them and neighboring layers.

After the growth, heterostructures were further processed. Circular mesa structures were formed using the reactive ion etching-inductively coupled plasma dry etching method. The diameters of the photodiodes were $300 \mu \mathrm{m}$. Electrical contacts were made by the deposition of $\mathrm{Ti} / \mathrm{Au}$ metallization using the magnetron sputtering method. After dicing, sample photodetectors were mounted onto test sub-assemblies using wire bonding. Finally, dark current, noise, and optical characterizations were performed.

\section{Results and Discussion}

\subsection{Dark Current Characteristics}

Dark current-voltage characteristics were measured for each photodiode in a wide range of temperatures using a setup consisting of Keithley 2612A source-measure instrument and Janis CCS-150 closed-cycle cryocooler. Samples were isolated from the environmental background radiation using a cold shield, which was cooled to around $10 \mathrm{~K}$ during the measurements. Differential-resistance-area product $\left(R_{d} A\right)$ as a function of bias was calculated from experimental I-V data. In Figure $3 a, b, J-V$ and $R_{d} A-V$ curves for considered photodiodes at $210 \mathrm{~K}$ are shown, respectively. This temperature was chosen as it corresponds to the one achievable through miniature three-stage thermoelectric coolers. Large differences in electrical characteristics between particular photodetectors 
were observed. The lowest dark current density was obtained for the $\mathrm{p}-\mathrm{B}_{\mathrm{p} \_ \text {bulk }}-\mathrm{i}-\mathrm{n}$ bariode, whereas the highest was for the $\mathrm{p}-\mathrm{i}-\mathrm{n}$ diode. Comparison between bariodes indicated that $\mathrm{p}-\mathrm{B}_{\mathrm{p} \_\mathrm{SL}}-\mathrm{i}-\mathrm{n}$ has a higher dark current. Both unbiased barrier photodiodes had similar values of $R_{0} A$ parameter of about $17 \Omega \mathrm{cm}^{2}$ for $\mathrm{p}-\mathrm{B}_{\mathrm{p} \_ \text {bulk }}-\mathrm{i}-\mathrm{n}$ and $\sim 18 \Omega \mathrm{cm}^{2}$ for $\mathrm{p}-\mathrm{B}_{\mathrm{p} \_\mathrm{SL}}-\mathrm{i}-\mathrm{n}$. However, for the latter device, it was the highest value whereas $\mathrm{p}-\mathrm{B}_{\mathrm{p} \_ \text {bulk }}-\mathrm{i}-\mathrm{n}$ achieved a higher value of $\sim 100 \Omega \mathrm{cm}^{2}$ with a small reverse bias of $104 \mathrm{mV}$. The classic p-i-n photodiode had a maximum $R_{d} A$ value of $2.4 \Omega \mathrm{cm}^{2}$ for zero bias. It is noteworthy that the photodetectors in this paper were not passivated, which could further decrease the dark current density.
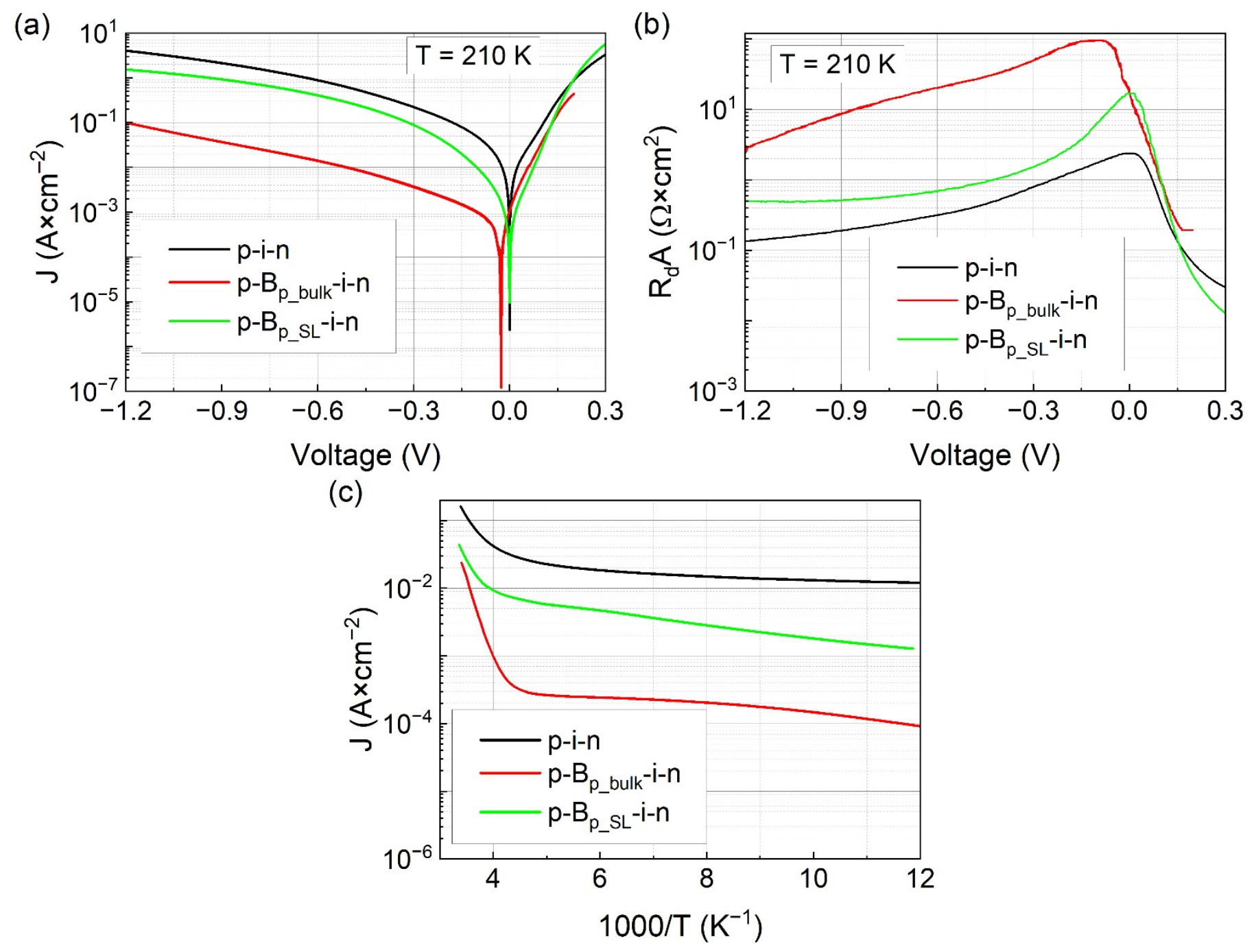

Figure 3. (a) Dark current density versus voltage and (b) differential resistance and area product versus voltage for $p-i-n$, p-B $\mathrm{B}_{\text {p_bulk }}-\mathrm{i}-\mathrm{n}$, and p- $\mathrm{B}_{\mathrm{p}_{-} \mathrm{SL}}-\mathrm{i}-\mathrm{n}$ photodiodes at 210 K. (c) Dark current density versus $1000 / \mathrm{T}$ for all photodiodes at a reverse bias of $50 \mathrm{mV}$.

In Figure 3c, dark current densities at $-50 \mathrm{mV}$ bias are plotted as a function of reciprocal temperature. The $\mathrm{p}$-i-n photodiode had the highest dark current density in the entire temperature range of $77 \mathrm{~K}-300 \mathrm{~K}$. The $\mathrm{p}-\mathrm{B}_{\mathrm{p}_{-} \text {bulk }}-\mathrm{i}-\mathrm{n}$ bariode had the smallest dark current density and outperformed the $\mathrm{p}-\mathrm{B}_{\mathrm{p}_{-} \mathrm{SL}} \mathrm{S}^{-\mathrm{i}-\mathrm{n}}$ by more than one order of magnitude for $\mathrm{T}<200 \mathrm{~K}$. In Table 2, activation energies $\mathrm{E}_{\mathrm{a} 2}$ and $\mathrm{E}_{\mathrm{a} 3}$ obtained from the analysis of the curves in Figure $3 c$ and their corresponding temperature ranges are given. All photodiodes had very small $(<10 \mathrm{meV})$ activation energies in low-temperature ranges $\left(\Delta \mathrm{T}_{2}\right.$ and $\left.\Delta \mathrm{T}_{3}\right)$, which suggests surface leakage channel as the main shunt current source. A more detailed analysis is needed to identify a specific mechanism. The behavior of photodiodes differs 
more at higher temperatures $\left(\Delta \mathrm{T}_{1}\right)$. The activation energies $\mathrm{E}_{\mathrm{a} 1}$ for the $\mathrm{p}-\mathrm{B}_{\mathrm{p} \_\mathrm{SL}} \mathrm{i}-\mathrm{n}$ bariode and the $\mathrm{p}-\mathrm{i}-\mathrm{n}$ photodiode were close to half of their bandgap energy at $300 \mathrm{~K}\left(\mathrm{E}_{\mathrm{g}_{-} 300 \mathrm{~K}}\right)$, which were equal to $\approx 250 \mathrm{meV}$ and $235 \mathrm{meV}$, respectively. These values indicate that the operation of these detectors in the $\Delta \mathrm{T}_{1}$ temperature range is limited by the generationrecombination ( $g-r)$ component of the dark current and/or shunt currents since it was shown that they can exhibit similar behavior and are influenced by the defect states in the junction area [24]. On the other hand, $\mathrm{p}-\mathrm{B}_{\mathrm{p} \_ \text {bulk }}-\mathrm{i}-\mathrm{n}$ had the highest activation energy, which was closer to the value of $\mathrm{E}_{\mathrm{g} \_300 \mathrm{~K}} \approx 250 \mathrm{meV}\left(\mathrm{E}_{\mathrm{a} 1} \approx 0.88 \times \mathrm{E}_{\mathrm{g} \_300 \mathrm{~K}}\right)$. This suggests that both diffusion and g-r dark current components are limiting its performance, with the former being the dominant one. The values of $\mathrm{E}_{\mathrm{g}_{-} 300 \mathrm{~K}}$ for $\mathrm{p}-\mathrm{i}-\mathrm{n}$ photodiode were estimated using the Varshni relation, which is described in Section 3.3. On the other hand, the $E_{g_{-} \_300 \mathrm{~K}}$ for both bariodes was determined from measurements of spectral current responsivity $\mathrm{R}_{\mathrm{I}}$ at $300 \mathrm{~K}$ (not shown in the paper).

Table 2. Activation energies and corresponding temperature ranges for $p-i-n, p-B_{p}$ bulk $-i-n$, and p-B_sL-i-n photodiodes.

\begin{tabular}{ccccccc}
\hline Photodetector & $\boldsymbol{\Delta} \mathrm{T}_{\mathbf{1}}$ & $\mathrm{E}_{\mathbf{a} \mathbf{1}}(\mathbf{m e V})$ & $\boldsymbol{\Delta} \mathrm{T}_{\mathbf{2}}$ & $\mathrm{E}_{\mathbf{a} 2}(\mathbf{m e V})$ & $\Delta \mathrm{T}_{\mathbf{3}}$ & $\mathrm{E}_{\mathbf{a} 3}(\mathbf{m e V})$ \\
\hline p-i-n & $>244 \mathrm{~K}$ & 111 & $100-244 \mathrm{~K}$ & 2.5 & $<100 \mathrm{~K}$ & 1.4 \\
p-B p_bulk $^{-\mathrm{i}-\mathrm{n}}$ & $>240 \mathrm{~K}$ & 220 & $112-240 \mathrm{~K}$ & 2.6 & $<112 \mathrm{~K}$ & 9.3 \\
p-B p_SL-i-n $^{-}$ & $>260 \mathrm{~K}$ & 132 & $104-260 \mathrm{~K}$ & 9.2 & $<104 \mathrm{~K}$ & 6.8 \\
\hline
\end{tabular}

\subsection{Noise Characteristics}

The setup used for low-frequency noise measurements and the small-signal equivalent circuit of a photodiode were described in Ref. [25]. In Figure 4a, power spectral densities measured at $\mathrm{T}=200 \mathrm{~K}$ for the low and high bias voltages are shown. In general, power spectral densities exhibit $1 / \mathrm{f}$ dependence, but some Lorentzian $\left(S_{\mathrm{i}} \sim 1 /\left(1+(\mathrm{f} / \text { const. })^{2}\right)\right.$ inclusions appear, especially for the low biased detector with a bulk AlSb barrier. The analysis of the noise signal in the time domain, illustrated in Figure $4 \mathrm{~b}$, reveals that Lorentzian is connected with random telegraph noise (RTN). Such noise is attributed to the carrier capture/emission by extended defects present in the depletion region [26]. At a small voltage bias of $-10 \mathrm{mV}$, the low-frequency noise magnitude is the lowest for the $\mathrm{p}-\mathrm{B}_{\mathrm{p} \_ \text {bulk }}-\mathrm{i}-\mathrm{n}$ detector. The significant difference in the magnitude is especially observed for low bias voltage and at low frequencies. For $\mathrm{U}=-500 \mathrm{mV}, \mathrm{p}-\mathrm{i}-\mathrm{n}$ photodiode had the highest noise magnitude in the entire measured frequency range, whereas $\mathrm{p}-\mathrm{B}_{\mathrm{p} \_}$bulk $-\mathrm{i}-\mathrm{n}$ had the smallest. The $\mathrm{p}-\mathrm{B}_{\mathrm{p} \_\mathrm{SL}} \mathrm{i}-\mathrm{n}$ was in-between, however, its $\mathrm{S}_{\mathrm{i}}$ decreased to the level of $\mathrm{p}-\mathrm{B}_{\mathrm{p} \_ \text {bulk }}-\mathrm{i}-\mathrm{n}$ at $\mathrm{f} \approx 10 \mathrm{kHz}$.
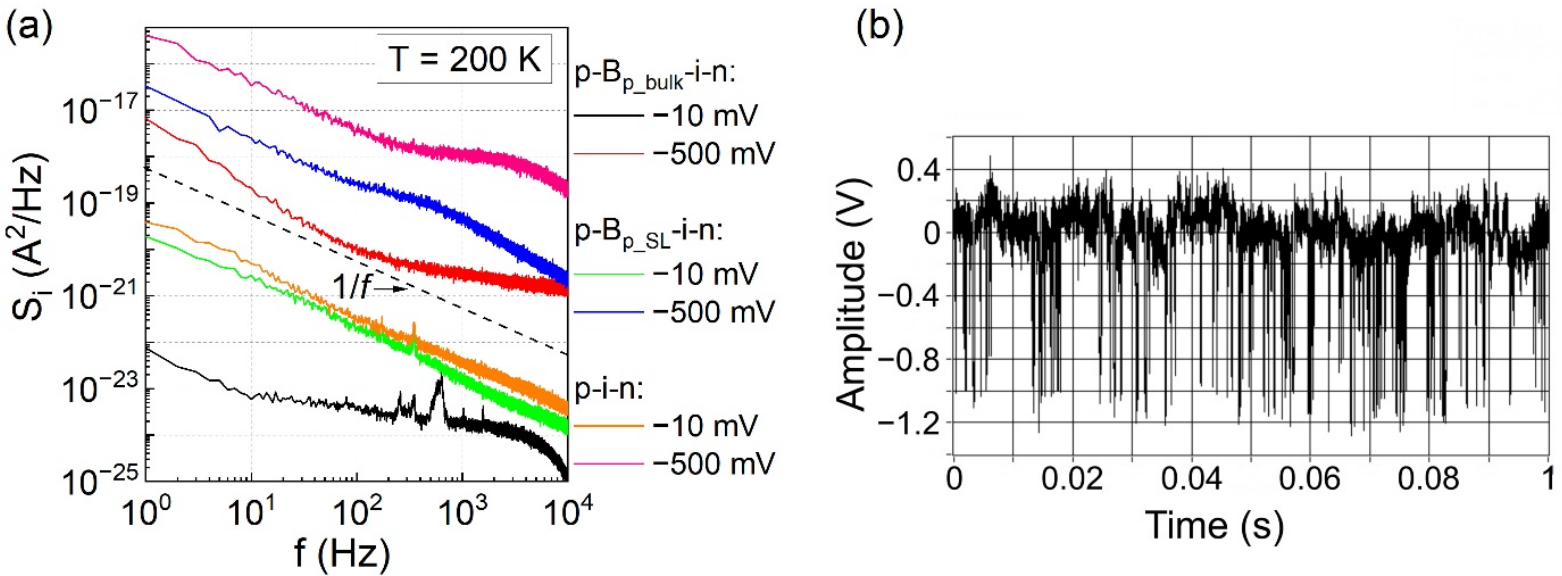

Figure 4. (a) The noise power spectral density versus frequency for considered photodiodes, measured at $200 \mathrm{~K}$ for two bias points. (b) Noise signal in the time domain for $\mathrm{p}-\mathrm{B}_{\mathrm{p} \_ \text {bulk }}-\mathrm{i}-\mathrm{n}$ structure recorded the output of transimpedance amplifier $\left(\mathrm{k}_{\mathrm{iu}}=10^{8} \mathrm{~V} / \mathrm{A}\right)$, at $\mathrm{T}=200 \mathrm{~K}$ and $\mathrm{U}=-50 \mathrm{mV}$. 
In Figure $5 \mathrm{a}, \mathrm{b}$, power spectral density magnitude $\mathrm{S}_{\mathrm{i}}(\mathrm{f}=1 \mathrm{~Hz})$ measured at $\mathrm{T}=84 \mathrm{~K}$ and $T=200 \mathrm{~K}$ are shown as a function of bias current $\mathrm{I}$. The dashed line in this figure follows dependence $S_{i}(f=1 \mathrm{~Hz}) \sim \mathrm{I}^{2}$. The measured characteristics $S_{\mathrm{i}}(\mathrm{I})$ match $\mathrm{S}_{\mathrm{i}}(\mathrm{I}) \sim \mathrm{I}^{2}$ dependence closely. There is no significant difference in the $S_{i}(I)$ magnitude for three considered types of photodetectors. If squared, dependence between $\mathrm{S}_{\mathrm{i}}(\mathrm{I})$ and I holds, the noise coefficient can be defined as $\alpha=\mathrm{S}_{\mathrm{i}}(\mathrm{f}=1 \mathrm{~Hz}) / \mathrm{I}^{2}$. The noise coefficients as a function of temperature are shown in Figure $5 \mathrm{~b}$. In this experiment, the noise was measured at voltage bias $\mathrm{U}=-50 \mathrm{mV}$. In the low-temperature region $(\mathrm{T} \approx 84 \mathrm{~K})$, the noise coefficient for all three structures is within the range of $1 \times 10^{-9}-2 \times 10^{-8} \mathrm{~Hz}^{-1}$. The current-temperature characteristics (see Figure 3c) show that in the low-temperature region, the leakage shunt current $I_{s h}$ dominates. Different values of noise coefficient $\alpha_{\mathrm{sh}}=\mathrm{S}_{\mathrm{i}}(\mathrm{f}=1 \mathrm{~Hz}) /\left(\mathrm{I}_{\mathrm{sh}}\right)^{2}$, related to the shunt current, have been reported in the literature. For InAs/GaSb SL devices, $\alpha_{\mathrm{sh}}$ is within the range of $3 \times 10^{-10}-6 \times 10^{-6} \mathrm{~Hz}^{-1}$ [21,27]. Our values of $\alpha_{\mathrm{sh}}$ lie in the middle of that range and change with the temperature only slightly. In the high-temperature region, the diffusion and generation-recombination currents dominate the total current. It was shown that such current, especially the diffusion component, has a much lower noise coefficient $[18,21,27-29]$. For detectors with InAs/GaSb SL absorber, $\alpha_{\mathrm{g}-\mathrm{r}}=4.8 \times 10^{-9} \mathrm{~Hz}^{-1}$ and $\alpha_{\text {diff }}=1.9 \times 10^{-10} \mathrm{~Hz}^{-1}$ were found for generation-recombination and diffusion current, respectively [19]. In the high-temperature region, the noise coefficient decreases slightly for $\mathrm{p}-\mathrm{i}-\mathrm{n}, \mathrm{p}-\mathrm{B}_{\mathrm{p} \_\mathrm{SL}}-\mathrm{i}-\mathrm{n}$ because the shunt current is still significant for these structures as compared to the diffusion current. For $\mathrm{p}-\mathrm{B}_{\mathrm{p}_{-} \text {bulk }}-\mathrm{i}-\mathrm{n}$, with low shunt current, the noise coefficient drops suggestively reaching a value of $1 \times 10^{-11} \mathrm{~Hz}^{-1}$, which is much lower than the best (lowest) results found by us in the literature [19]. This translates into good noise performance of the $\mathrm{p}-\mathrm{B}_{\mathrm{p} \_ \text {bulk }}-\mathrm{i}-\mathrm{n}$ detector at temperatures, where current is limited by its diffusion component.

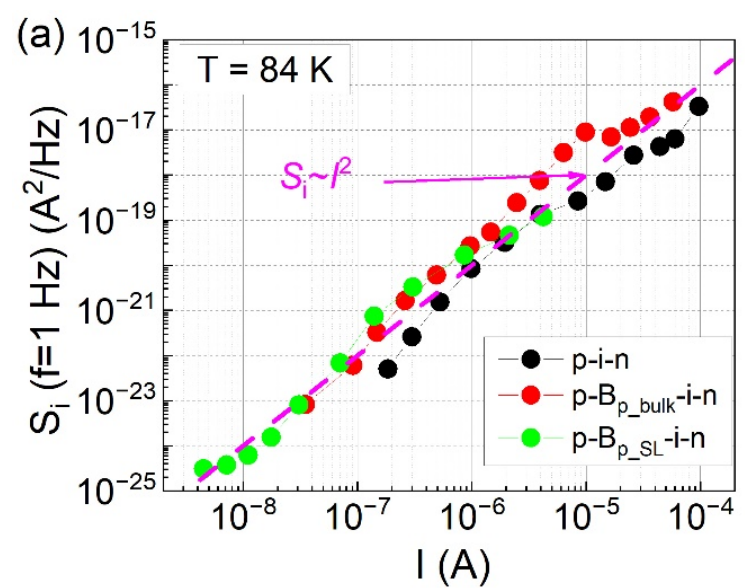

(c)

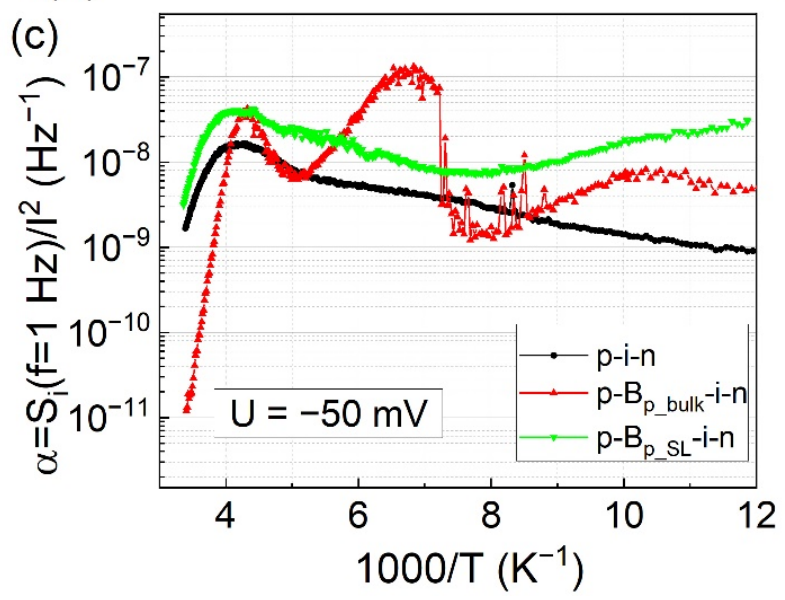

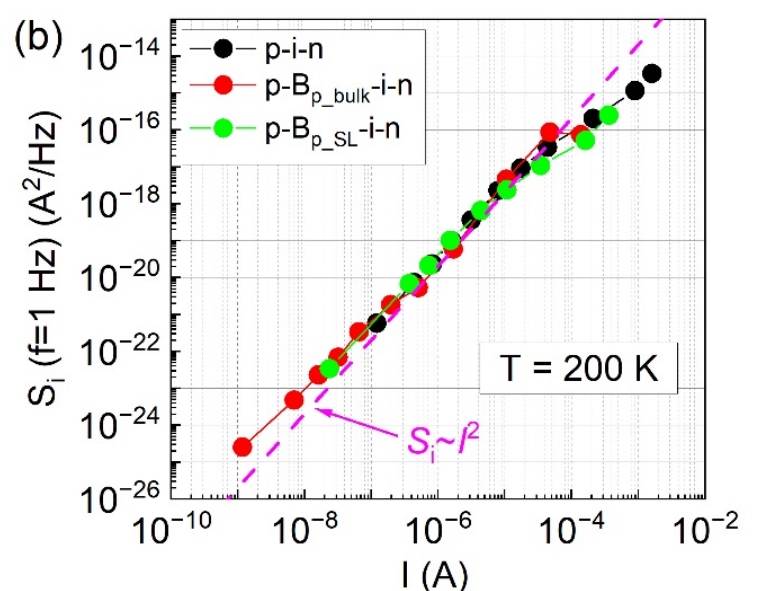

I (A)

Figure 5. $\mathrm{S}_{\mathrm{i}}(\mathrm{I})$ characteristics measured at (a) $\mathrm{T}=84 \mathrm{~K}$ and (b) $\mathrm{T}=200 \mathrm{~K}$. (c) The noise coefficient $\alpha$, obtained for noise measurements at voltage bias $\mathrm{U}=-50 \mathrm{mV}$, as a function of reciprocal temperature for considered photodiodes. 


\subsection{Optical Characteristics}

Spectral current responsivity measurements were performed in the range of 3-6 $\mu \mathrm{m}$ at $210 \mathrm{~K}$. The experimental setup consisted of Horiba MicroHR motorized monochromator equipped with SiC-based IR source and ruled grating with blaze wavelength of $5000 \mathrm{~nm}$. The optical signal was mechanically chopped and detected using the Stanford Research Systems SR830 DSP lock-in amplifier. A calibrated lithium tantalate pyroelectric detector with a $\mathrm{BaF}_{2}$ window was used to measure the reference signal. Sample photodetectors were placed in Janis CCS-150K closed-cycle cryocooler with a KBr window.

In Figure 6a-c, results of spectral current responsivity $\left(R_{I}\right)$ measurements of considered photodetectors are shown for two reverse bias values each. Long-wavelength absorption edge $\lambda_{c}$ was determined to be $\sim 4.7 \mu \mathrm{m}$ for all analyzed photodiodes. The cause of the slight differences in $\lambda_{c}$ originates mainly from the variations in both the composition and thicknesses of InSb- and GaAs-like interfaces in the InAs/GaSb superlattice in the absorption region. The former were not taken into account during the simulation of $2 \theta / \omega$ curves, in which binary interfaces were assumed. The latter are given in Table 1 in the section Fabrication of InAs/GaSb superlattice photodetectors. Dips in the spectra at wavelengths in the range of 3.3-3.5 $\mu \mathrm{m}$ in Figure $6 \mathrm{a}-\mathrm{c}$ are caused by the absorption of radiation by water vapor present in the measurement chamber.
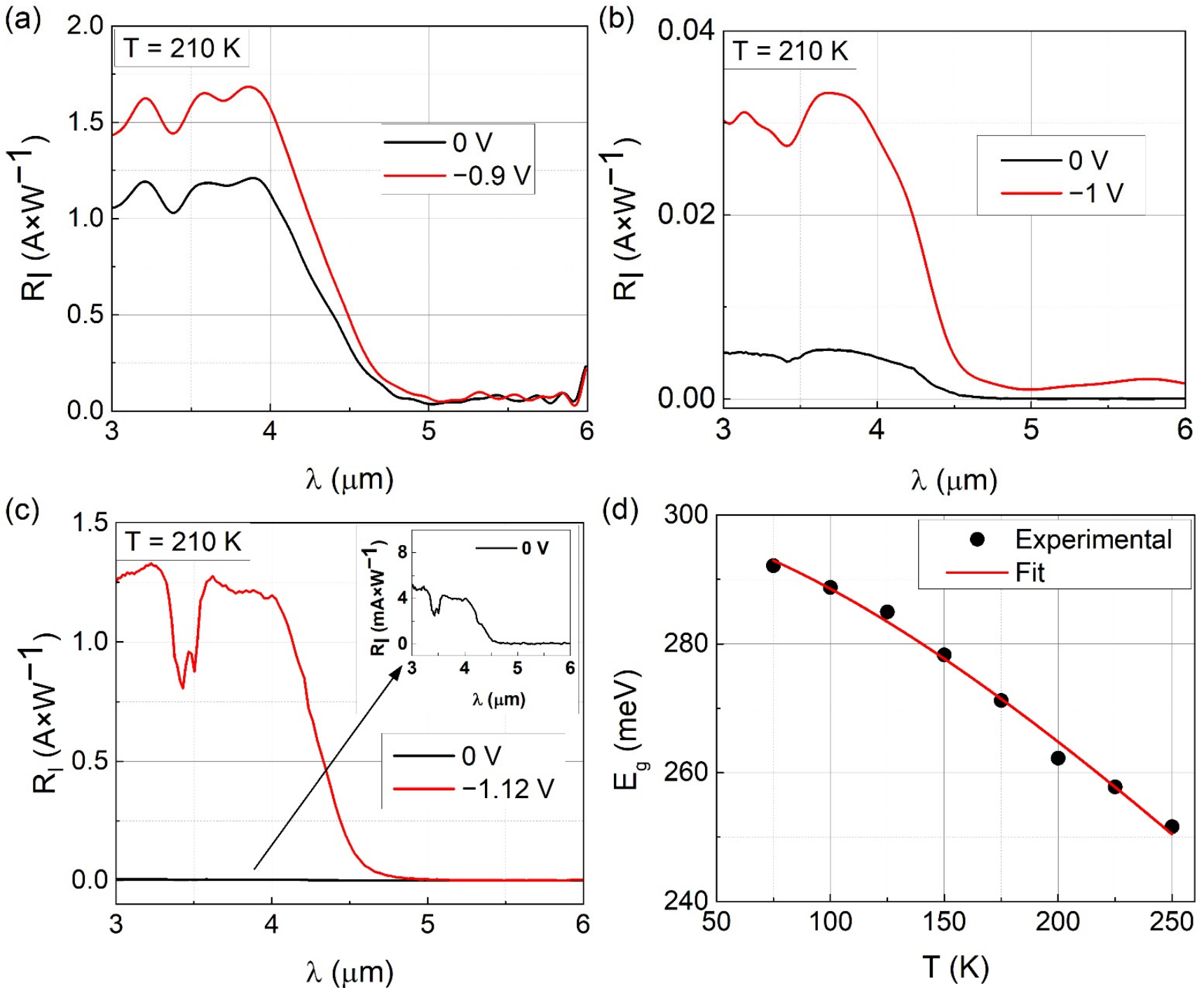

Figure 6. Spectral current responsivity $\left(\mathrm{R}_{\mathrm{I}}\right)$ for $(\mathbf{a}) \mathrm{p}-\mathrm{i}-\mathrm{n},(\mathbf{b}) \mathrm{p}-\mathrm{B}_{\mathrm{p} \_ \text {bulk }}-\mathrm{i}-\mathrm{n}$, and (c) p- $\mathrm{B}_{\mathrm{p} \_\mathrm{SL}}-\mathrm{i}-\mathrm{n}$ photodiodes at $210 \mathrm{~K}$, at two biases. (d) Bandgap energy of p-i-n photodiode absorber region at various temperatures and fitted Varshni relation. 
In Figure 6d, experimental values of bandgap energy $E_{g}$ determined from $R_{I}$ measurements at various temperatures for $\mathrm{p}-\mathrm{i}-\mathrm{n}$ photodiode are plotted. The data were fitted to Varshni relation (red line in Figure $6 \mathrm{~d}$ ), and the following parameters were obtained: $\mathrm{E}_{\mathrm{g} \_0}=300 \mathrm{meV}, \alpha=4.09 \times 10^{-4} \mathrm{eV} \times \mathrm{K}^{-1}$. The $\beta=270 \mathrm{~K}$ was assumed as it is most commonly used for InAs/GaSb type-II superlattices [30,31]. The fitting was performed for $\mathrm{p}$-i-n photodiode only. For bariodes, $\mathrm{R}_{\mathrm{I}}$ spectra were measured only at $2-3$ different temperatures. The values of $E_{g}$ of absorber region in $p-i-n, p-B_{p \_b u l k}-i-n$, and p-B $B_{p \_s L}-i-n$ photodiodes at $210 \mathrm{~K}$ were $263 \mathrm{meV}, 271 \mathrm{meV}$, and $273 \mathrm{meV}$, respectively. As was mentioned, the difference in $\mathrm{E}_{\mathrm{g}}$ results from variation in thickness of InSb-like and GaAs-like interfaces in InAs/GaSb superlattice (Table 1).

The measured spectral current responsivity of $\mathrm{p}-\mathrm{i}-\mathrm{n}$ photodiode increased with reverse bias from $\sim 1.2 \mathrm{~A} \times \mathrm{W}^{-1}$ for $\mathrm{U}=0 \mathrm{~V}$ to $\sim 1.65 \mathrm{~A} \times \mathrm{W}^{-1}$ for $\mathrm{U}=-0.9 \mathrm{~V}$. It also had the highest values of $\mathrm{R}_{\mathrm{I}}$, namely $\sim 1.65-1.68 \mathrm{~A} \times \mathrm{W}^{-1}$ for wavelengths in the range from $3.55 \mu \mathrm{m}$ to $4 \mu \mathrm{m}$. The photodiode with the AlSb barrier had the lowest $\mathrm{R}_{\mathrm{I}}$, which was less than $0.04 \mathrm{~A} \times \mathrm{W}^{-1}$ in the entire measurement range. Two reverse biases were considered at $0 \mathrm{~V}$ and about $-1 \mathrm{~V}$. The presence of $\mathrm{p}-\mathrm{n}$ junction in all described heterostructures should enable a passive operation of these photodetectors without bias. This is clear for the $p-i-n$ diode, for which spectral current responsivity is nearly the same with and without bias. In principle, the addition of a barrier for electrons should not negatively impact carrier transport in the heterostructure and thus device operation. This is under the condition that the barrier layer will not introduce parasitic valence band offset between absorption and/or contact regions. Based on the curves shown in Figure $6 b, c$ for $U=0 \mathrm{~V}$, it is clear that an unwanted barrier for holes in the valence band is present. Both for $\mathrm{p}-\mathrm{B}_{\mathrm{p} \_ \text {bulk }}-\mathrm{i}-\mathrm{n}$

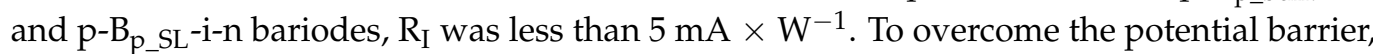
an external bias was necessary.

Spectral current responsivity was measured for various biases from $0 \mathrm{~V}$ to $1 \mathrm{~V}$. The values of the voltage result from the limitations of the measurement setup at the time. In the case of the $\mathrm{p}-\mathrm{i}-\mathrm{n}$ photodiode, the responsivity did not change with increasing voltage. For bariodes, both $\mathrm{p}-\mathrm{B}_{\mathrm{p} \_ \text {bulk }}-\mathrm{i}-\mathrm{n}$ and $\mathrm{p}-\mathrm{B}_{\mathrm{p} \_\mathrm{SL}}-\mathrm{i}-\mathrm{n}, \mathrm{R}_{\mathrm{I}}$ increased with reverse bias. Despite the improvement, the $R_{I}$ for the photodetector with the AlSb barrier was very small, $<40 \mathrm{~mA} \times \mathrm{W}^{-1}$. This indicates that the applied external electric field failed to completely overcome the parasitic barrier in the valence band and improve device operation. On the other hand, $\mathrm{p}-\mathrm{B}_{\mathrm{p} \_\mathrm{SL}}-\mathrm{i}-\mathrm{n}$ bariode reached maximum $\mathrm{R}_{\mathrm{I}}=1.33 \mathrm{~A} \times \mathrm{W}^{-1}$, which corresponds to about 260 times improvement. This proves that AlSb/GaSb superlattice plays a much better role as an electron barrier than the bulk AlSb layer. Nevertheless, further optimization of the AlSb/GaSb structure is necessary to eliminate the parasitic valence band offset and improve device performance.

\subsection{Specific Detectivity}

Finally, the values of specific detectivity $D^{*}$ based on two semi-empirical approximations $\left(\mathrm{D}_{\text {approx} \_\_1}^{*} \mathrm{D}_{\text {approx} . \_2}\right.$ ) and measured $\left(\mathrm{D}_{\text {exp }}^{*}\right) \mathrm{S}_{\mathrm{i}}$ were determined and juxtaposed. The calculations were performed for two bias voltages $(0 \mathrm{~V}$ and $\sim-1 \mathrm{~V})$, for $\lambda=4 \mu \mathrm{m}$, $\mathrm{T}=210 \mathrm{~K}$, and $\mathrm{f}=10 \mathrm{kHz}$. In general, the $\mathrm{D}^{*}$ for a bandwidth of $1 \mathrm{~Hz}$ can be defined as follows:

$$
\mathrm{D}^{*}=\frac{\mathrm{R}_{\mathrm{I}} \sqrt{\mathrm{A}}}{\sqrt{S_{i}}}
$$

where $R_{I}$ is the spectral current responsivity, $A$ is the area of the detector, and $S_{i}$ is the noise power spectral density at a given frequency. The $S_{i}$ can be further described as:

$$
S_{i}=S_{i \_t h e r m a l}+S_{i \_S c h o t t k y}+S_{i \_l f}+S_{i \_o t h e r}=\frac{4 k_{B} T}{R}+2 q I+\alpha \frac{I^{b}}{f}+S_{i \_o t h e r}
$$

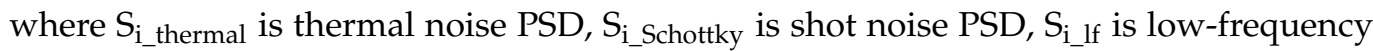
noise PSD, $S_{i_{-} \text {other }}$ is the sum of other (not included) noise power spectral densities, $\mathrm{k}_{\mathrm{B}}$ is Boltzmann's constant, $T$ is temperature, $R$ is dynamic resistance, $q$ is the elementary 
charge, $\mathrm{I}$ is current, $\mathrm{b}$ is the power coefficient, which is usually assumed equal to $2, \alpha$ is the noise coefficient, and $\mathrm{f}$ is frequency. In our case, the $\mathrm{S}_{\text {lf }}$ can be expressed as in Equation (3), assuming $\alpha=2$, due to the behavior of the data shown in Figure 5a. To most accurately determine the specific detectivity it is necessary to measure the noise PSD for a specific device. However, when this is not an option, it is possible to use semi-empirical approximations of $S_{i}$. The first approximation $\left(S_{i}\right.$ approx._1 $)$ includes only thermal and shot noise components. It is calculated using I and $\mathrm{R}$ extracted from the measured currentvoltage curves of a photodetector. The second approximation $\left(\mathrm{S}_{\mathrm{i} \_a p p r o x} \_2\right)$ includes thermal, shot, and low-frequency noise components. On top of I and R, it requires information about the noise coefficient $\alpha$. In this approach, it is sufficient to measure $\alpha$ for a specific bias (not necessarily the voltage for which the detectivity will be determined), for example, $-50 \mathrm{mV}$ in this paper as shown in Figure $5 c$. Then, $S_{i \_ \text {lf }}$ can be estimated using the expression given in Equation (3) for voltage bias, for which the $\mathrm{S}_{\mathrm{i}}(\mathrm{I}) \sim \mathrm{I}^{2}$. Both approximations can be further simplified, depending on the bias of the photodiode. For unbiased photodetectors, in the absence of photocurrent due to background radiation, the specific detectivity will be limited only by thermal noise. The accuracy of these approximations depends on the interaction between the aforementioned noise components, which is related to the type of the photodetector, the quality of its structure, and processing. Furthermore, their usage may lead to both under- and overestimation of $\mathrm{D}^{*}$, especially under improper assumptions.

The first approximation $\left(\mathrm{S}_{\mathrm{i} \_ \text {approx__}}\right)$ was used to estimate the specific detectivity $\mathrm{D}_{\text {approx__1 }}^{*}$ for unbiased and biased photodiodes in question. For $\mathrm{U}=0 \mathrm{~V}$ the $\mathrm{S}_{\mathrm{i}_{-} \text {Schottky }}$ was about four, two, and one order of magnitude smaller than $\mathrm{S}_{\mathrm{i} \text { _thermnal }}$ for $\mathrm{p}-\mathrm{i}-\mathrm{n}, \mathrm{p}-\mathrm{B}_{\mathrm{p} \_ \text {bulk }}-\mathrm{i}-\mathrm{n}$, and $\mathrm{p}-\mathrm{B}_{\mathrm{p}_{-} \mathrm{SL}}-\mathrm{i}-\mathrm{n}$, respectively. The non-zero shot noise component originates from the photocurrent generated due to the background radiation. The following voltages, which were used during spectral current responsivity measurements, were used in the calculation of $\mathrm{D}^{*}$ under bias: $-0.9 \mathrm{~V}$ for $\mathrm{p}-\mathrm{i}-\mathrm{n},-1 \mathrm{~V}$ for $\mathrm{p}-\mathrm{B}_{\mathrm{p} \_ \text {bulk }}-\mathrm{i}-\mathrm{n}$, and $-1.12 \mathrm{~V}$ for $\mathrm{p}-\mathrm{B}_{\mathrm{p} \_\mathrm{SL}}-\mathrm{i}-\mathrm{n}$. In this case, the average of power spectral density magnitude of noise measured at $200 \mathrm{~K}$ and $225 \mathrm{~K}$, for $-1 \mathrm{~V}$ bias was taken as an approximation for the noise at $\mathrm{T}=210 \mathrm{~K}$. Based on the $S_{i}(T)$ function, it was determined that the character of changes of $S_{i}$ in this temperature range allow for the use of such an approach. The results of the calculations under the following assumptions, $\mathrm{T}=210 \mathrm{~K}, \lambda=4 \mu \mathrm{m}$, and $\mathrm{f}=10 \mathrm{kHz}$, are shown in Table 3 . At zero bias, the highest values of $\mathrm{D}_{\text {approx._1 }}^{*}, \mathrm{D}^{*}$ approx._2, and $\mathrm{D}^{*}$ exp were obtained for $\mathrm{p}$-i-n photodiode and were equal to $1.61 \times 10^{10}$ Jones, $1.61 \times 10^{10}$ Jones, and $6.16 \times 10^{9}$ Jones, respectively. They were about one to three orders of magnitude higher than for both bariodes, for which $\mathrm{D}_{\text {approx._1 }}^{*}=1.43-1.52 \times 10^{8}$ Jones, $\mathrm{D}_{\text {approx._2 }}^{*}=7.05 \times 10^{7}-1.52 \times 10^{8}$ Jones, and $\mathrm{D}^{*}$ exp $=1.04-1.25 \times 10^{8}$ Jones. The main reason behind lower values was negligible current responsivity of bariodes in photovoltaic operation mode, which canceled out any performance improvement due to the decrease in noise. The $\mathrm{p}-\mathrm{B}_{\mathrm{p}_{-} \mathrm{SL}}-\mathrm{i}-\mathrm{n}$ device outperformed $\mathrm{p}-\mathrm{i}-\mathrm{n}$ by about one order of magnitude in terms of $\mathrm{S}_{\mathrm{i}}$, while $\mathrm{p}-\mathrm{B}_{\mathrm{p}_{2} \text { bulk }}-\mathrm{i}-\mathrm{n}$ by about two orders of magnitude. On the other hand, p-i-n achieved between 250 and 280 times larger $\mathrm{R}_{\mathrm{I}}$ than other photodetectors.

Table 3. The values of specific detectivity $\left(D^{*}\right)$ calculated for given biases, at $\lambda=4 \mu \mathrm{m}$, at $\mathrm{T}=210 \mathrm{~K}$, at $\mathrm{f}=10 \mathrm{kHz}$.

\begin{tabular}{|c|c|c|c|c|c|c|c|}
\hline Photodiode & $\mathrm{U}(\mathrm{V})$ & $\begin{array}{c}S_{\text {i_approx } \cdot 1} \\
\left(A^{2} / H z\right)\end{array}$ & $\begin{array}{c}\mathrm{S}_{\mathrm{i} \_ \text {approx} \cdot 22} \\
\left(\mathrm{~A}^{2} / \mathrm{Hz}\right)\end{array}$ & $\begin{array}{c}S_{i \_\exp } \\
\left(A^{2} / H z\right)\end{array}$ & $\begin{array}{c}\mathrm{D}^{*} \text { approx} \cdot \_1 \\
\text { (Jones) }\end{array}$ & $\begin{array}{c}\mathrm{D}^{*} \text { approx } \cdot 2 \\
\text { (Jones) }\end{array}$ & $\begin{array}{l}D^{*} \exp \\
\text { (Jones) }\end{array}$ \\
\hline \multirow{2}{*}{$\mathrm{p}-\mathrm{i}-\mathrm{n}$} & 0 & $3.45 \times 10^{-24}$ & $3.45 \times 10^{-24}$ & $3.35 \times 10^{-24}$ & $1.61 \times 10^{10}$ & $1.61 \times 10^{10}$ & $6.16 \times 10^{9}$ \\
\hline & -0.9 & $6.55 \times 10^{-22}$ & $3.89 \times 10^{-18}$ & $1.45 \times 10^{-19}$ & $1.63 \times 10^{9}$ & $2.11 \times 10^{7}$ & $1.1 \times 10^{8}$ \\
\hline \multirow{2}{*}{$p-B_{p \_b u l k}-i-n$} & 0 & $9.8 \times 10^{-26}$ & $1.11 \times 10^{-25}$ & $3.59 \times 10^{-26}$ & $1.43 \times 10^{8}$ & $1.35 \times 10^{8}$ & $2.4 \times 10^{8}$ \\
\hline & -1 & $1.37 \times 10^{-24}$ & $1.63 \times 10^{-23}$ & $4.97 \times 10^{-20}$ & $2.44 \times 10^{8}$ & $7.05 \times 10^{7}$ & $1.3 \times 10^{6}$ \\
\hline \multirow{2}{*}{$\mathrm{p}-\mathrm{B}_{\mathrm{p} \_\mathrm{SL}}-\mathrm{i}-\mathrm{n}$} & 0 & $4.87 \times 10^{-25}$ & $4.88 \times 10^{-25}$ & $7.28 \times 10^{-25}$ & $1.52 \times 10^{8}$ & $1.52 \times 10^{8}$ & $1.25 \times 10^{8}$ \\
\hline & -1.12 & $3.27 \times 10^{-22}$ & $2.27 \times 10^{-18}$ & $9.34 \times 10^{-20}$ & $1.76 \times 10^{9}$ & $2.12 \times 10^{7}$ & $1.04 \times 10^{8}$ \\
\hline
\end{tabular}

The values of specific detectivity calculated using the first approximation decreased with a bias for simple photodiode mainly due to larger noise and increased a little for 
bariodes. For $\mathrm{p}$-i-n photodiode, $\mathrm{D}_{\text {approx._1 }}$ decreased one order of magnitude with larger

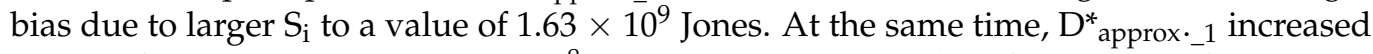
slightly for $\mathrm{p}-\mathrm{B}_{\mathrm{p}_{-} \text {bulk }}-\mathrm{i}-\mathrm{n}$ to $2.44 \times 10^{8}$ Jones and about an order of magnitude for $\mathrm{p}-\mathrm{B}_{\mathrm{p}_{-} \mathrm{SL}}{ }^{-}$ $\mathrm{i}$-n to $1.76 \times 10^{9}$ Jones. The former is due to a similar increase in noise (14 times) and a decrease in $R_{I}$ (4.64 times). On the other hand, $S_{i}$ increased 681 times while $R_{I} 300$ times for the latter $\left(D^{*}\right.$ is proportional to $\left.1 / \sqrt{ } S_{i}\right)$. The values of $S_{i}$ approx__2 were from one to four orders of magnitude larger than those of $S_{i_{-} a p p r o x} \cdot 1$. Consequently, the values of $D_{\text {approx._2 }}^{*}$ decreased for all photodetectors, as compared to $\mathrm{D}_{\text {approx._1 }}^{*}$, due to a large contribution of low-frequency noise estimated using semi-empirical approximation.

At zero bias, the values of $S_{i \_a p p r o x} \cdot 1$ were close to the experimental ones, especially so for $\mathrm{p}$-i-n photodiode. As a result, $\mathrm{D}^{*}$ behaved in the same way, which validates the use of this approximation in such conditions. On the other hand, at higher biases, the following was observed: $S_{i \_a p p r o x} \cdot 1<<S_{i \_ \text {exp }}$ and $D^{*}$ approx•_1 $>>D^{*}$ exp. This suggests that using only Johnson and shot noise components are not sufficient for proper approximation of the detectivity. This approach underestimated $S_{i}$ for larger biases by two to four orders of magnitude, which proves that assumed noise components are not dominant for these structures and in these operating conditions. For $\mathrm{p}$-i-n photodiode, $\mathrm{D}^{*}{ }_{\text {exp }}$ decreased more than an order of magnitude to $1.1 \times 10^{8}$ Jones as compared to approximated value. A much smaller change was observed for the $\mathrm{p}-\mathrm{B}_{\mathrm{p}_{-} \mathrm{SL}}-\mathrm{i}-\mathrm{n}$ photodetector $\left(\mathrm{D}^{*}{ }_{\exp }=1.04 \times 10^{8}\right.$ Jones). On the other hand, the $\mathrm{p}-\mathrm{B}_{p_{-} \text {bulk }}-\mathrm{i}-\mathrm{n}$ device exhibited a decrease of two orders of magnitude to $1.3 \times 10^{6}$ Jones. As a result, it had the worst performance even though it had the best noise characteristics.

The second approximation yielded values of $S_{i_{\_} a p p r o x} \cdot 2$ for $p-i-n$ and $p-B_{p \_S L}-i-n$, which were comparable to those estimated using the first approximation and the experimental ones. For p- $\mathrm{B}_{p_{-} \_ \text {bulk }}-\mathrm{i}-\mathrm{n}$ the $\mathrm{S}_{\mathrm{i} \_a p p r o x} \cdot 2$ was close to the $\mathrm{S}_{\mathrm{i}_{\_} \text {approx} \cdot \_1}$, and both of them were a little larger ( 2.75 times) than $S_{i_{i} \text { exp. }}$ This difference originates from the assumption of the relation $\mathrm{Si}(\mathrm{I}) \sim \mathrm{I}^{2}$, which does not hold for this bariode for small currents (Figure $5 b$ ). These results are expected since the $1 / \mathrm{f}$ noise is a non-equilibrium component, which vanishes as the current approaches zero. Consequently, the values of $\mathrm{D}^{*}$ approx._2

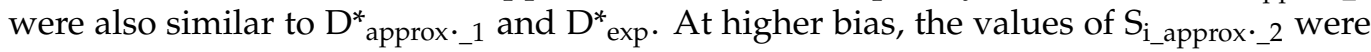
overestimated by one and two orders of magnitude for $\mathrm{p}-\mathrm{i}-\mathrm{n}$ and $\mathrm{p}-\mathrm{B}_{\mathrm{p}_{-} \mathrm{SL}}-\mathrm{i}-\mathrm{n}$ photodiodes, respectively. This suggests that the relation of $\mathrm{S}_{\mathrm{i}}(\mathrm{I}) \sim \mathrm{I}^{2}$ does not hold for larger dark currents. This can be further confirmed by the data in Figure $5 b$, which shows this deviation for I $>4 \times 10^{-5}$ A for p-i-n photodiode and I $>1 \times 10^{-5}$ A for $\mathrm{p}-\mathrm{B}_{\mathrm{p} \_\mathrm{SL}}-\mathrm{i}-\mathrm{n}$ bariode. At this point, the data for $S_{i}(I)$ for large currents were fitted to a power function without the assumption of $b=2$ in Equation (3). The following values $\alpha$ and $b$ were obtained: for $\mathrm{p}$-i-n photodiode $\alpha=5 \times 10^{-12}, \mathrm{~b}=1.195$; for $\mathrm{p}-\mathrm{B}_{\mathrm{p} \_\mathrm{SL}} \mathrm{i}-\mathrm{n}$ bariode $\alpha=2.5 \times 10^{-12}$, $\mathrm{b}=1.195$. These values were used to recalculate the $\mathrm{S}_{\mathrm{i}}$ using the second approximation. The following results were obtained: for p-i-n $S_{i \_a p p r o x} \_2=2.82 \times 10^{-19}\left(\mathrm{~A}^{2} / \mathrm{Hz}\right)$; for $\mathrm{p}-\mathrm{B}_{\mathrm{p} \_ \text {SL }}$-i-n $\mathrm{S}_{\mathrm{i} \_a p p r o x} \cdot \mathrm{z}_{2}=6.29 \times 10^{-20}\left(\mathrm{~A}^{2} / \mathrm{Hz}\right)$. Both values are very close to the experimental ones for these photodetectors. This proves that this approximation approach is correct given sufficient information about $\alpha$ and $/$ or $S_{i}(I)$ relation. On the other hand, the value of $S_{i \_a p p r o x} \_2$ was three orders of magnitude smaller than $S_{i \_ \text {exp }}$ for $p-B_{p \_S L}-i-n$. This indicates that there are components of noise present in this detector other than thermal, shot, and low-frequency. Figure $5 \mathrm{a}, \mathrm{b}$ show that the assumption of $\mathrm{b}=2$ holds for a wide range of currents, which proves that the proposed second approximation method can be useful in the determination of specific detectivity for many photodetectors.

As it was shown, the omission of the low-frequency noise during the calculation of the specific detectivity is unjustified without additional knowledge about its magnitude. Nevertheless, it is a common practice [32-37], even though the detector is voltage-biased. This approach can lead to a significant overestimation of detectivity in the detection of slowly varying IR sources. 


\section{Conclusions}

In this paper, electrical, noise, and optical characteristics of $\mathrm{p}-\mathrm{i}-\mathrm{n}, \mathrm{p}-\mathrm{B}_{\mathrm{p} \_ \text {bulk }}-\mathrm{i}-\mathrm{n}$, and $\mathrm{p}-\mathrm{B}_{\mathrm{p}_{-} \mathrm{SL}}-\mathrm{i}-\mathrm{n}$ photodiodes were presented. The main subject was focused on device operation in HOT conditions. Both dark current and noise analysis showed that $\mathrm{p}-\mathrm{B}_{\mathrm{p} \_ \text {bulk }}-\mathrm{i}-\mathrm{n}$ bariode had the best performance in these areas whereas $\mathrm{p}-\mathrm{i}-\mathrm{n}$ photodiode was the worst and $\mathrm{p}-\mathrm{B}_{\mathrm{p} \_\mathrm{sL}}-\mathrm{i}-\mathrm{n}$ placed in-between. Optical characterization showed that at zero bias, $\mathrm{p}-\mathrm{i}-\mathrm{n}$ photodiode had the highest spectral current responsivity, while both bariodes had much lower values of $R_{I}$. With higher bias $R_{I}$ for $p-i-n$ was still the highest, however, a larger

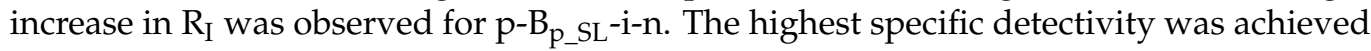
for $\mathrm{p}-\mathrm{i}-\mathrm{n}$ detector in photovoltaic operation mode. Both $\mathrm{p}-\mathrm{i}-\mathrm{n}$ and $\mathrm{p}-\mathrm{B}_{\mathrm{p} \_\mathrm{SL}}-\mathrm{i}-\mathrm{n}$ photodiodes had almost the same values of $\mathrm{D}^{*}$ at $\sim-1 \mathrm{~V}$ reverse bias. Obtained results indicate that at zero bias, both proposed electron barriers introduced parasitic valence band offsets, which effectively blocked the generated photocurrent. As such, the design of the bariodes could not be fully utilized. This suggests that with better optimization of electron barrier, a further improvement in the performance of bariode with $\mathrm{AlSb} / \mathrm{GaSb}$ barrier could be achieved. This would be especially important at smaller bias, at which the gain from better noise performance in bariodes is more pronounced.

The specific detectivity of the photodiodes in question was determined using two semi-empirical approximations and empirical data. A simple method of incorporating the low-frequency noise contribution into the detectivity calculation, without time-consuming measurements, has been proposed. This approach is valid as long as the $S_{i}(I) \sim I^{2}$ relation used in this approximation holds. It was shown that neglecting the low-frequency noise component can lead to a significant overestimation of detectivity.

Author Contributions: Conceptualization, K.C. and A.J.; methodology, K.C., Ł.C., I.S., A.J.; validation, K.C., Ł.C., I.S. and A.J.; formal analysis, K.C., Ł.C.; investigation, K.C., Ł.C., I.S. and A.J.; resources, A.J.; data curation, K.C.; writing—original draft preparation, K.C., Ł.C.; writing-review and editing, K.C., I.S., E.P.-P. and A.J.; visualization, K.C.; supervision, A.J.; project administration, A.J.; funding acquisition, A.J. All authors have read and agreed to the published version of the manuscript.

Funding: This work was partially supported by the National Centre for Research and Development (project No. POIR.04.01.04-00-0123/17 and by the Minister of Education and Science of the Republic of Poland within the Regional Initiative of Excellence program for years 2019-2022, project number 027/RID/2018/19, the amount granted 11999900 PLN.

Institutional Review Board Statement: Not applicable.

Informed Consent Statement: Not applicable.

Data Availability Statement: Data sharing does not apply to this article.

Conflicts of Interest: The authors declare no conflict of interest.

\section{References}

1. Nguyen, B.-M.; Hoffman, D.; Wei, Y.; Delaunay, P.-Y.; Hood, A.; Razeghi, M. Very High Quantum Efficiency in Type-II InAs/GaSb Superlattice Photodiode with Cutoff of $12 \mu \mathrm{m}$. Appl. Phys. Lett. 2007, 90, 231108. [CrossRef]

2. Jasik, A.; Sankowska, I.; Pierścińska, D.; Regiński, K.; Pierściński, K.; Kubacka-Traczyk, J. Blueshift of Bandgap Energy and Reduction of Non-Radiative Defect Density Due to Precise Control of InAs-on-GaSb Interface in Type-II InAs/GaSb Superlattice. J. Appl. Phys. 2011, 110, 123103. [CrossRef]

3. Brown, G.J. Type-II InAs/GaInSb Superlattices for Infrared Detection: An Overview; Andresen, B.F., Fulop, G.F., Eds.; SPIE: Bellingham, WA, USA, 2005; pp. 65-77. [CrossRef]

4. Perez, J.-P.; Durlin, Q.; Christol, P. Ga-Free InAs/InAsSb Type-II Superlattice (T2SL) Photodetector for High Operating Temperature in the Midwave Infrared Spectral Domain. In Proceedings of the International Conference on Space Optics-ICSO 2018, Chania, Greece, 9-12 October 2018; Volume 11180. [CrossRef]

5. Klipstein, P. XBn Barrier Photodetectors Based on InAsSb with High Operating Temperatures. Opt. Eng. 2011, 50, 061002. [CrossRef]

6. Sai-Halasz, G.A.; Tsu, R.; Esaki, L. A New Semiconductor Superlattice. Appl. Phys. Lett. 1977, 30, 651-653. [CrossRef]

7. Lee, H.J.; Ko, S.Y.; Kim, Y.H.; Nah, J. Strain-Induced the Dark Current Characteristics in InAs/GaSb Type-II Superlattice for Mid-Wave Detector. J. Semicond. 2020, 41, 062302. [CrossRef] 
8. Wang, F.; Xu, Z.; Bai, Z.; Li, H.; Zhou, Y.; Chen, J.; He, L. Fabrication of a $1024 \times 1024$ Format Long Wavelength Infrared Focal Plane Array Based on Type-II Superlattice and Barrier Enhanced Structure. Infrared Phys. Technol. 2021, 115, 103700. [CrossRef]

9. Bandara, S.; Tidrow, M.; Aitcheson, L.; Zeng, L.; Baril, N. III-V Material Superlattice Infrared Focal Plane Array Technology. In Proceedings of the Infrared Technology and Applications XLVII; Fulop, G.F., Kimata, M., Zheng, L., Andresen, B.F., Miller, J.L., Eds.; SPIE: Bellingham, WA, USA, 2021; p. 17. [CrossRef]

10. Gautam, N.; Myers, S.; Barve, A.V.; Klein, B.; Smith, E.P.; Rhiger, D.; Plis, E.; Kutty, M.N.; Henry, N.; Schuler-Sandy, T.; et al. Band Engineered HOT Midwave Infrared Detectors Based on Type-II InAs/GaSb Strained Layer Superlattices. Infrared Phys. Technol. 2013, 59, 72-77. [CrossRef]

11. Maimon, S.; Wicks, G.W. NBn Detector, an Infrared Detector with Reduced Dark Current and Higher Operating Temperature. Appl. Phys. Lett. 2006, 89, 151109. [CrossRef]

12. Gautam, N.; Myers, S.; Barve, A.V.; Klein, B.; Smith, E.P.; Rhiger, D.R.; Dawson, L.R.; Krishna, S. High Operating Temperature Interband Cascade Midwave Infrared Detector Based on Type-II InAs/GaSb Strained Layer Superlattice. Appl. Phys. Lett. 2012, 101, 021106. [CrossRef]

13. Tian, Z.; Cai, Z.; Yang, R.Q.; Mishima, T.D.; Santos, M.B.; Johnson, M.B.; Klem, J.F. Interband Cascade Infrared Photodetectors. In Proceedings of the Quantum Sensing and Nanophotonic Devices VII; Razeghi, M., Sudharsanan, R., Brown, G.J., Eds.; SPIE: Bellingham, WA, USA, 2010; Volume 7608, pp. 590-597. [CrossRef]

14. Delga, A. 8-Quantum cascade detectors: A review. In Mid-Infrared Optoelectronics; Tournié, E., Cerutti, L., Eds.; Woodhead Publishing Series in Electronic and Optical Materials; Woodhead Publishing: Duxford, UK, 2020; pp. 337-377. ISBN 978-0-08-102709-7. [CrossRef]

15. Savich, G.R.; Pedrazzani, J.R.; Sidor, D.E.; Maimon, S.; Wicks, G.W. Dark Current Filtering in Unipolar Barrier Infrared Detectors. Appl. Phys. Lett. 2011, 99, 121112. [CrossRef]

16. Klipstein, P.; Klin, O.; Grossman, S.; Snapi, N.; Yaakobovitz, B.; Brumer, M.; Lukomsky, I.; Aronov, D.; Yassen, M.; Yofis, B.; et al. XBn Barrier Detectors for High Operating Temperatures; Razeghi, M., Sudharsanan, R., Brown, G.J., Eds.; SPIE: Bellingham, WA, USA, 2010; p. 76081V. [CrossRef]

17. Ting, D.Z.-Y.; Hill, C.J.; Soibel, A.; Keo, S.A.; Mumolo, J.M.; Nguyen, J.; Gunapala, S.D. A High-Performance Long Wavelength Superlattice Complementary Barrier Infrared Detector. Appl. Phys. Lett. 2009, 95, 023508. [CrossRef]

18. Zhu, L.; Zhu, L.; Zhu, L.; Deng, Z.; Huang, J.; Huang, J.; Guo, H.; Chen, L.; Lin, C.; Lin, C.; et al. Low Frequency Noise-Dark Current Correlations in HgCdTe Infrared Photodetectors. Opt. Express 2020, 28, 23660-23669. [CrossRef]

19. Ramos, D.; Delmas, M.; Ivanov, R.; Höglund, L.; Costard, E.; Hellström, P.-E.; Malm, G. 1/f Noise and Dark Current Correlation in Midwave InAs/GaSb Type-II Superlattice IR Detectors. Phys. Status Solidi A 2021, 218, 2000557. [CrossRef]

20. Razeghi, M.; Haddadi, A.; Chen, G.; Hoang, A.M.; Chevallier, R.; Callewaert, F. Low-Frequency Noise in Mid-Wavelength Infrared InAs/GaSb Type-II Superlattice Based Focal Plane Arrays. In Proceedings of the Infrared Technology and Applications XL; SPIE: Bellingham, WA, USA, 2014; Volume 9070, pp. 437-445. [CrossRef]

21. Meng, C.; Li, J.; Yu, L.; Wang, X.; Han, P.; Yan, F.; Xu, Z.; Xu, Z.; Chen, J.; Ji, X.; et al. Investigation of a Noise Source and Its Impact on the Photocurrent Performance of Long-Wave-Infrared InAs/GaSb Type-II Superlattice Detectors. Opt. Express 2020, 28, 14753-14761. [CrossRef] [PubMed]

22. Craig, A.P.; Letka, V.; Carmichael, M.; Golding, T.; Marshall, A.R. InAsSb-Based Detectors on GaSb for near-Room-Temperature Operation in the Mid-Wave Infrared. Appl. Phys. Lett. 2021, 118, 251103. [CrossRef]

23. Jasik, A.; Sankowska, I.; Ratajczak, J.; Wawro, A.; Smoczyński, D.; Czuba, K.; Wzorek, M. Atomically Smooth Interfaces of Type-II InAs/GaSb Superlattice on Metamorphic GaSb Buffer Grown in 2D Mode on GaAs Substrate Using MBE. Curr. Appl. Phys. 2019, 19, 120-127. [CrossRef]

24. Rehm, R.; Lemke, F.; Schmitz, J.; Wauro, M.; Walther, M. Limiting Dark Current Mechanisms in Antimony-Based Superlattice Infrared Detectors for the Long-Wavelength Infrared Regime; Andresen, B.F., Fulop, G.F., Hanson, C.M., Norton, P.R., Eds.; SPIE: Bellingham, WA, USA, 2015; p. 94510N. [CrossRef]

25. Ciura, Ł.; Kolek, A.; Gawron, W.; Kowalewski, A.; Stanaszek, D. Measurements of Low Frequency Noise of Infrared PhotoDetectors with Transimpedance Detection System. Metrol. Meas. Syst. 2014, 21, 461-472. [CrossRef]

26. Brunner, A.; Rubaldo, L.; Destefanis, V.; Chabuel, F.; Kerlain, A.; Bauza, D.; Baier, N. Improvement of RTS Noise in HgCdTe MWIR Detectors. J. Electron. Mater. 2014, 43, 3060-3064. [CrossRef]

27. Ciura, Ł.; Kolek, A.; Jureńczyk, J.; Czuba, K.; Jasik, A.; Sankowska, I.; Papis-Polakowska, E.; Kaniewski, J. Noise-Current Correlations in InAs/GaSb Type-II Superlattice Midwavelength Infrared Detectors. IEEE Trans. Electron Devices 2016, 63, 4907-4912. [CrossRef]

28. Ciura, Ł.; Kopytko, M.; Martyniuk, P. Low-Frequency Noise Limitations of InAsSb-, and HgCdTe-Based Infrared Detectors. Sens. Actuators Phys. 2020, 305, 111908. [CrossRef]

29. Ciura, Ł.; Kolek, A.; Jureńczyk, J.; Czuba, K.; Jasik, A.; Sankowska, I.; Kaniewski, J. 1/f Noise Modeling of InAs/GaSb Superlattice Mid-Wavelength Infrared Detectors. Opt. Quantum Electron. 2017, 50, 36. [CrossRef]

30. Klein, B.; Plis, E.; Kutty, M.N.; Gautam, N.; Albrecht, A.; Myers, S.; Krishna, S. Varshni Parameters for InAs/GaSb Strained Layer Superlattice Infrared Photodetectors. J. Phys. Appl. Phys. 2011, 44, 075102. [CrossRef] 
31. Czuba, K.; Sankowska, I.; Jureńczyk, J.; Jasik, A.; Papis-Polakowska, E.; Kaniewski, J. Influence of Be Doping Placement in InAs/GaSb Superlattice-Based Absorber on the Performance of MWIR Photodiodes. Semicond. Sci. Technol. 2017, 32, 055010. [CrossRef]

32. Teng, Y.; Hao, X.; Zhu, H.; Zhu, H.; Liu, J.; Huai, Y.; Li, M.; Liu, M.; Xing, W.; Chen, B.; et al. Demonstration of MOCVD-Grown Long-Wavelength Infrared InAs/GaSb Superlattice Focal Plane Array. IEEE Access 2021, 9, 60689-60694. [CrossRef]

33. More, V.M.; Kim, Y.; Jeon, J.; Shin, J.C.; Lee, S.J. Dual-Band Unipolar Barrier Infrared Photodetector Based on InGaAsSb Bulk and Type-II InAs/GaSb Superlattice Absorbers. J. Alloys Compd. 2021, 868, 159195. [CrossRef]

34. Wu, D.; Dehzangi, A.; Razeghi, M. Demonstration of Mid-Wavelength Infrared NBn Photodetectors Based on Type-II InAs/InAs 1-x $\mathrm{Sb}_{\mathrm{x}}$ Superlattice Grown by Metal-Organic Chemical Vapor Deposition. Appl. Phys. Lett. 2019, 115, 061102. [CrossRef]

35. Hao, X.; Deng, Z.; Huang, J.; Huang, Y.; Yang, H.; Teng, Y.; Zhao, Y.; Wu, Q.; Li, X.; Liu, J.; et al. Demonstration of a DualBand InAs/GaSb Type-II Superlattice Infrared Detector Based on a Single Heterojunction Diode. IEEE J. Quantum Electron. 2019, 56. [CrossRef]

36. Wu, D.H.; Dehzangi, A.; Zhang, Y.Y.; Razeghi, M. Demonstration of Long Wavelength Infrared Type-II InAs/InAs1-XSbx Superlattices Photodiodes on GaSb Substrate Grown by Metalorganic Chemical Vapor Deposition. Appl. Phys. Lett. 2018, 112, 241103. [CrossRef]

37. Martyniuk, P.; Gawron, W.; Stepien, D.; Benyahia, D.; Kowalewski, A.; Michalczewski, K.; Rogalski, A. Demonstration of Mid-Wave Type-II Superlattice InAs/GaSb Single Pixel Barrier Detector with GaAs Immersion Lens. IEEE Electron Device Lett. 2016, 37, 64-66. [CrossRef] 